\title{
金ナノワイヤ構造・コンダクタンスの 結晶方位依存性
}

\author{
大 島 義 文 \\ 東京工業大学大学院総合理工学研究科材料物理科学専攻 恶 226-8502 神奈川県横浜市緑区長津田 4259-J 1-3 \\ (2005 年 4 月 20 日受理)
}

\section{Structure and Electrical Conductance of Gold Nanowire Depending on the Crystalline Orientation of the Electrode}

\author{
Yoshifumi OsHIMA \\ Department of Material Science and Engineering, Interdisciplinary Graduate School of Science and Engineering, \\ Tokyo Institute of Technology \\ J 1-3, 4259 Nagatsuta, Midori-ku, Yokohama, Kanagawa 226-8502
}

(Received April 20, 2005)

\begin{abstract}
A new transmission electron microscope-scanning tunneling microscope (TEM-STM) system was developed in order to simultaneously investigate structure and electrical conductance of gold contacts in ultra high-vacuum TEM. We found that the gold contact parallel to the [001] or [111] direction of both electrodes became short neck, while the contact parallel to the [110] direction, long nanowire. When the contact was short neck, the electrical conductance changed stepwise at some points and did discontinuously at the other parts. In this case, the broad conductance peaks appeared in the histogram. On the other hand, when the contact was long nanowire, the conductance changed stepwise and showed an integer times the quantum unit of conductance $\left(\mathrm{G}_{0}=2 \mathrm{e}^{2} / \mathrm{h}\right)$. In the histogram, the sharp peaks appeared. These experimental results were qualitatively in agreement with the previous theoretical results based on the mesoscopic theory.
\end{abstract}

\section{1. 緒言}

微細加工技術の進歩や走査型トンネル顕微鏡（Scanning Tunneling Microscope: STM）などの測定技術向上に より，原子レベルの物性制御が可能となりつつある。 STM 法は, 表面の構造や電子状態に関する情報を得る だけでなく, 原子レベルで平坦な表面上での原子のマニ ピュレーションなど, 原子加工ツールとしても用いられ ている。最近, STM のティップを試料面に接触したり 引離したりする過程で, 原子レベルの金属接点を形成し た際，そのコンダクタンスが階段状に変化する様子が見 出され, 注目を集めた ${ }^{1 \sim 3)}$ 。その後, このようなコンダ クタンスの階段状変化は, STM 法（Fig. 1 (a)）や機械 的制御による破断法 (Mechanical Controllable Breaking Junction: MCBJ 法) ${ }^{4)}$ (Fig. 1 (b) ) によって見出されて いる。MCBJ 法は, STM 法に比べ接触や引離し過程に

E-mail: ohshima@materia.titech.ac.jp
おける変位量を 2 桁程度小さくできることから，準静的 な構造変化を観察できると考えられていた。つまり, MCBJ 法で測定されたコンダクタンス変化は, 常に似た ような振る舞いになると思われたが, 実際は, 測定ごと に異なる振る舞いを示す。Fig. 2 (a) は, 同じ条件で引 き離した場合の測定結果 2 例を示している。左のコンダ クタンスは, $4.5,2.9,2.4,1.6,0.9 \mathrm{G}_{0}$ と変化している。 一方, 右は, 4.2, 2.6, 1.75, $0.9 \mathrm{G}_{0}$ と変化しており, 前者とは異なる数值をとる。さらに, 同じ条件で変化さ せたにもかかわらず，コンダクタンスの滞在時間は左の ほうが 2 倍以上長い。そこで, 一般に, Fig. 2（b）に示 すように, 多数の金接点のコンダクタンス測定から得ら れたコンダクタンス・ヒストグラムから, 優先的に現れ るコンダクタンス值を求めている。金接点の場合, Fig. 2 （b）に示すように, コンダクタンス量子化単位（ $G_{0}=$ $\left.2 e^{2} / h=1 / 12.6 k \Omega\right)$ の整数倍が優先的に現れる。ここで $e$ は素電荷量, $h$ はプランク定数である。つまり, 金接 点は, 量子化コンダクタンスを示している1 4)。 
(a)

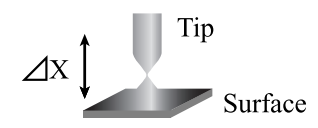

(b)

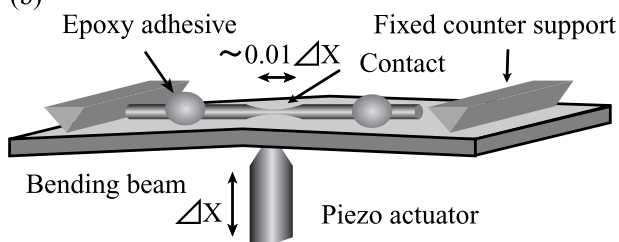

Fig. 1. (a) Illustration of STM method. The contact is directly elongated (contracted) by a piezo actuator. (b) Illustration of MCBJ method. The contact is elongated (contracted) by bending the beam using a piezo actuator. The displacement at the contact is about a few percent of one of the piezo actuator.

(a)

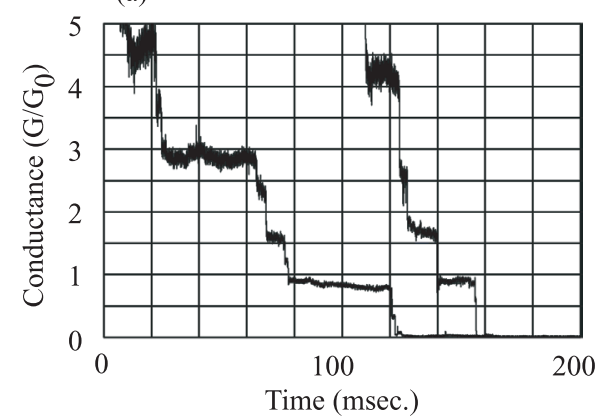

(b)

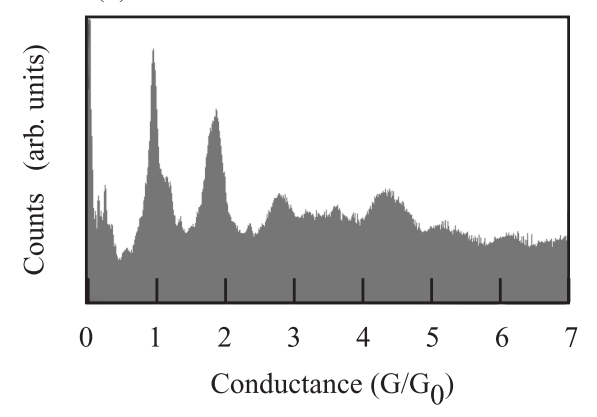

Fig. 2. (a) Two typical conductance curves of gold contact, which were obtained by the MCBJ method. The contact was elongated by increasing the bias voltage for the piezo actuator. The conductance was measured at applying the bias voltage of $60 \mathrm{mV}$ to the contact. (b) Typical conductance histogram of gold contact. This histogram clearly shows the conductance peaks at 1 , 2 and $3 \mathrm{G}_{0}\left(=2 \mathrm{e}^{2} / \mathrm{h}\right)$. Courtesy of Mr. Komiyama of Tokyo Institute of Technology.

金属接点のコンダクタンス計測は, 様々な元素で行わ れており, コンダクタンスの振る舞いが元素によって異 なることが明らかにされている。アルミニウムの場合, 接点を引つ張る過程, すなわち, 原子間距離を離す過程 で, コンダクタンスが増加する現象が見出されている5)。
これは，伝導に $\mathrm{s}$ 電子だけでなく, $\mathrm{p}$ 電子も寄与してい ること，そして，この $\mathrm{p}$ 電子の伝導が原子配列や原子間 距離に敏感であることで説明されている6,7)。また, 白 金単原子接点では, I-V 特性において非線形性が観測さ れている8)。これは, コンダクタンスに $\mathrm{d}$ 電子が奇与し ており,この d 電子の伝導チャンネルの透過率が接点に 印加されたバイアスに依存して変化するためと考えられ ている。このように金属接点のコンダクタンスは, 構成 原子の配列に依存することが特徵である。

一方，金接点は，原子間距離を離す過程において，コ ンダクタンスが一定であり, 測定ごとに異なる值を示す 理由は明らかになっていない。著者らは, この現象につ いて, 伝導に $\mathrm{s}$ 電子のみが寄与し, 金接点の結晶方位が 影響しているのではないかと考えた。接点を構成する原 子の配列とコンダクタンスの関係は, 理論計算の報告が いくつかあるものの 9 , 10), 実験の報告はほとんどない。 よって, 本研究は, 金接点の構造とコンダクタンスの関 係を明らかにするため, 透過型電子顕微鏡 (Transmission Electron Microscope: TEM）と走查型トンネル顕微鏡 (Scanning Tunneling Microscope: STM) を組み合わせた 手法（TEM-STM 法）を開発し, 構造とコンダクタンス の同時測定を行った。

\section{TEM-STM 法}

TEM-STM 法を用いることで, STM ティップとサン プル間に金接点，あるいは金ナノワイヤを作製し，その 原子構造を TEM で観察し, 同時に, そのコンダクタン スをSTM で計測できる。このような電子顕微鏡とプロ ーブ顕微鏡を組み合わせた手法は，ナノスケール材料の 研究開発に有効な手段であることが示されている11 13)。 中でも, 大西らは, 超高真空 TEM（Ultra High VacuumTEM: UHV-TEM）に組み込むことができる小型 STM ホ ルダーを作製し，金原子鎖のコンダクタンスが $1 \mathrm{G}_{0}$ で あることを直接示すことに成功し14), 注目を集めた。こ

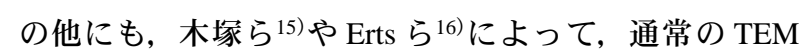
を用いた TEM-STM ホルダーの開発が行われ，金ナノワ イヤの構造とバリスティック伝導・拡散伝導の違いに関 する報告などがされている。

今回, 我々は, UHV-TEM 用 STM ホルダーを開発し, 金接点や金ナノワイヤの構造およびコンダクタンスを調 べた ${ }^{17)}$ 。使用した UHV-TEM（JEM-2000 VF）は, 電界 放射型電子銃を備えており, 高分解能観察ができる（加 速電圧 $200 \mathrm{kV}$ )。対物ポールピース (Objective Pole Piece: OPP）は，TEM-STM を実現するために特別な仕様とな っている18)。この OPP のギャップ内にゴニオメータと STM ホルダーを結合できるステージ（Stage）が用意さ 


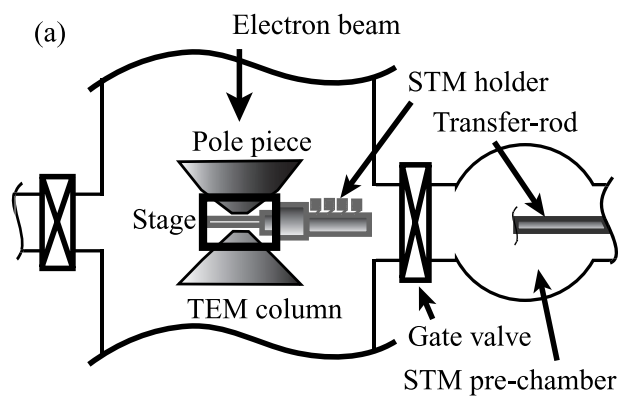

(b)

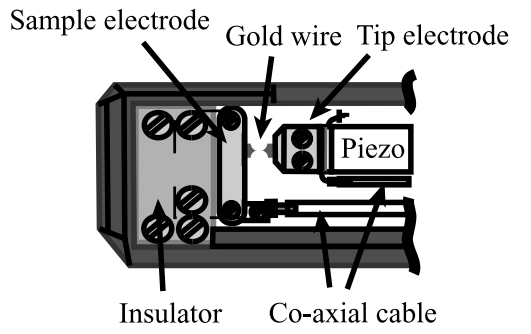

Fig. 3. (a) Design of the STM-TEM system for UHV-TEM. The STM holder is transferred through the STM prechamber to the stage which is placed at the center of the objective pole piece. The stage is attached to the goniometer of the TEM (not shown). (b) Illustration of the STM holder head. The STM tip stage is driven by a tube piezo and by an inchworm. A gold wire is placed between the tip and sample stage.

れており (Fig. 3 (a)), 開発した小型 STM ホルダーは, STM 予備チャンバー（STM pre-chamber）を通じて搬送 されるようになっている。この電子顕微鏡には, イオン スパッタポンプとターボ分子ポンプが取り付けられてお り, 試料室内を超高真空 $\left(<3 \times 10^{-8} \mathrm{~Pa}\right)$ に保つことが できる。ホルダー周りの圧力を $3 \times 10^{-8} \mathrm{~Pa}$ に保つこと で, 污染の影響がない金接点や金ナノワイヤを作製でき, 金ポイントコンタクトの I-V（電流-電圧）特性を再現 性よく測定することができる19)。

開発した小型 STM ホルダーの概観を Fig. 3 (b) に示 す。この STM ホルダーには, サンプル電極 (Sample electrode）とティップ電極（Tip electrode）があり，両電極 間に金ワイヤ（Gold wire）を張ることができる。金接 点や金ナノワイヤは，この金ワイヤを細くすることによ って得られる。両電極間に吊り下げれたナノワイヤが容 易に切れないように, 両電極の剛性をできる限り高くし ている。また, この STM ホルダーには, 探針の粗動と 微動機構があり, 粗動として, インチワーム（バーレ社 製）を用いてティップを軸方向に最大 $5 \mathrm{~mm}$ 動かすこと ができ, 微動として, チューブピエゾ素子を用いて 3 方 位にそれぞれ最大 $1 \mu \mathrm{m}$ を $0.1 \mathrm{~nm}$ オーダーで動かすこと ができる。この STM ホルダーは, ベリリウム銅で作製 し, ゴニオメータ・ステージは, チタンで作製している。

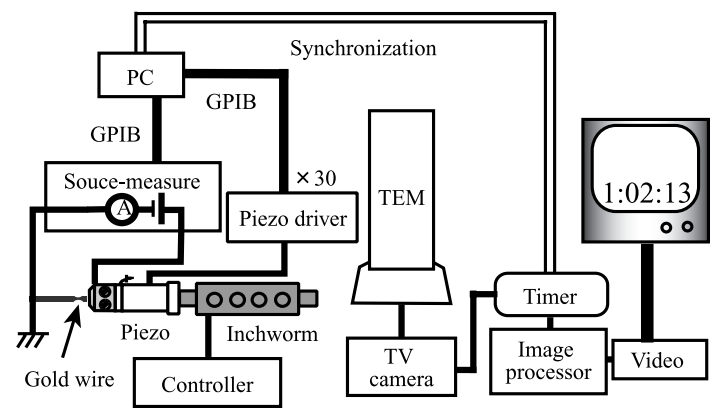

Fig. 4. Schematic illustration of the synchronized measurement method of the TEM-STM system. A source measurement unit was used for measuring the current, when the bias voltage $(12.9 \mathrm{mV})$ was applied between both electrodes. TEM images of the videotape were synchronized with the conductance measurement using the timer.

互いに異なる金属にした理由は，この 2 つが真空内で結 合した際にロックされないようにするためである。

Fig. 4 は, 開発したコンダクタンス計測システムであ る。チューブピエゾ動作やコンダクタンス計測は，パー ソナルコンピューター（PC）で制御した。コンダクタ ンス計測には, ソースメジャーユニット（ケイスレー社 製 Model 236）を用いて，ティップとサンプル電極間に $12.9 \mathrm{mV}$ を印加し, その電流值を読み取ることで行った。 この場合, コンダクタンスが $1 \mathrm{G}_{0}$ である金原子鎖では, $1 \mu \mathrm{A}$ 電流が流れる。コンダクタンスは, $\pm 0.01 \mathrm{G}_{0}$ 範囲 内の誤差で計測できる。また，コンダクタンス測定と TEM 観察像の同期は，PC とタイマー（Timer）の時間 を合わせ, タイマーをビデオ画面にスーパーインポーズ することによって実現した。

上記 2 端子測定結果からコンダクタンスを解析する 際，コンタクト領域外の残留抵抗については考慮しなか った ${ }^{20)}$ 。この理由は, 十分に太い金線における抵抗は, 数 $\Omega$ のオーダー程度であり, 一方, 金接点の抵抗は, 数百から数 $K \Omega$ であったからである。また，このコンダ クタンス計測において，電子線の影響が懸念された。そ こで, コンダクタンス計測中に電子線をオフにすること を試みた。その結果, ノイズレベル以外, 電流值は変わ らなかった。電子線照射による電流は, 1 原子列当たり $2 \times 10^{-17} \mathrm{~A}$ であり, 一方, 金接点の計測電流は, $8 \mathrm{G}_{0}$ に 対し， $8 \times 10^{-6} \mathrm{~A}$ であった。したがって，電子線照射に よる電流量は, コンダクタンス計測の電流量に比べ 10 桁以上低く，コンダクタンス測定に影響を与えない。

\section{3. 接点・ナノワイヤの作製}

金ナノワイヤは, ティップとサンプル電極間にくびれ が入った金ワイヤ（直径 $0.25 \mathrm{~mm}$ ）を橋渡しし，インチ 
ワームやピエゾを用いて引つ張ることによって得られ た。金ワイヤのくびれは, 塩化カルシウム溶液中にて電 解研磨によって得られており, 金ワイヤを引っ張った際 に金ナノワイヤが形成する箇所となる。金ワイヤを STM ホルダーに取り付け, STM 予備チャンバーにて, 真空 引きした後, $1 \mathrm{~A}$ の定電流を通電することによって, 約 1 日，金ワイヤのアニールを行った。これは，金ワイヤ からコンタミを除去するためである。また, アニールは, 金ワイヤを再結晶化させる効果もある。そして, STM ホルダーは, ゴニオステージへ搬送され, 金ワイヤは, インチワームを用いて切れるまでゆっくりと引き伸ばさ れた。これによって, 2 つの電極を形成した。これらの 電極の先端は, 高分解能 TEM 像を得るのに十分薄い膜 になっており,ピエゾを用いて互いに接近させることで, 金接点を得た。ただし，両電極が多結晶であるため, 接 点が得られた場所において, ティップ電極とサンプル電 極の結晶方位が一致していることはほとんどない。また, 接点近傍では格子歪が大きいため, 接点が細くなるにつ れて, その歪緩和から接点が破断してしまうことが多く, 単原子レベルの接点を得ることは困難であった。そこで, 結晶方位を揃えるため, 両電極間に $12.9 \mathrm{mV}$ 印加しなが ら，ピエゾを用いて，ティップ電極をサンプル電極に対 し押し込んだり, 引っ張り出す過程を繰り返した。この 過程を繰り返すことで, 接点近傍での格子歪が緩和し, やがて, 結晶方位が揃っていく傾向が見られた。さらに, 接点近傍に残留していたコンタミが完全に除去された。 この結果, 原子レベルで安定した接点を得ることができ た。ここで, 接点近傍にコンタミがある場合, 接点が融 解してしまい, 原子レベルの接点を得ることはできない。 これは, コンタミによる電子散乱によりジュール熱が発 生し, 局所的に温度が上昇してしまうためと推測してい る。

\section{4. 金ナノワイヤ構造の結晶方位依存性}

上記方法を用いて形成した金接点は，主に金ワイヤの 軸方向が [001， [111，［110］結晶方位となる構造に なった。Fig. 5 (a)〜 (c) は，それぞれ，[001]， [111]， [110］方位に平行な軸をもつ金接点の典型的な TEM 像 である。各 TEM 像の黒い点は, 金原子, あるいは, 電 子線入射方位に沿って並んだ金原子列に相当する。Fig. 5 (a) は, 結晶方位 [001］に平行な軸をもつ電極の接 点であり, 短いナノワイヤである。この場合, 電極の側 面は, 4 つの $\{111\}$ 面からなっている。[001］軸が 4 回対称性をもつことから, 電極は, (001) 層が積層して できたピラミッド形状であり, 接点は, 2 つのピラミッ ドの頂点が接するところである。Fig. 5 （b）は, 電極の

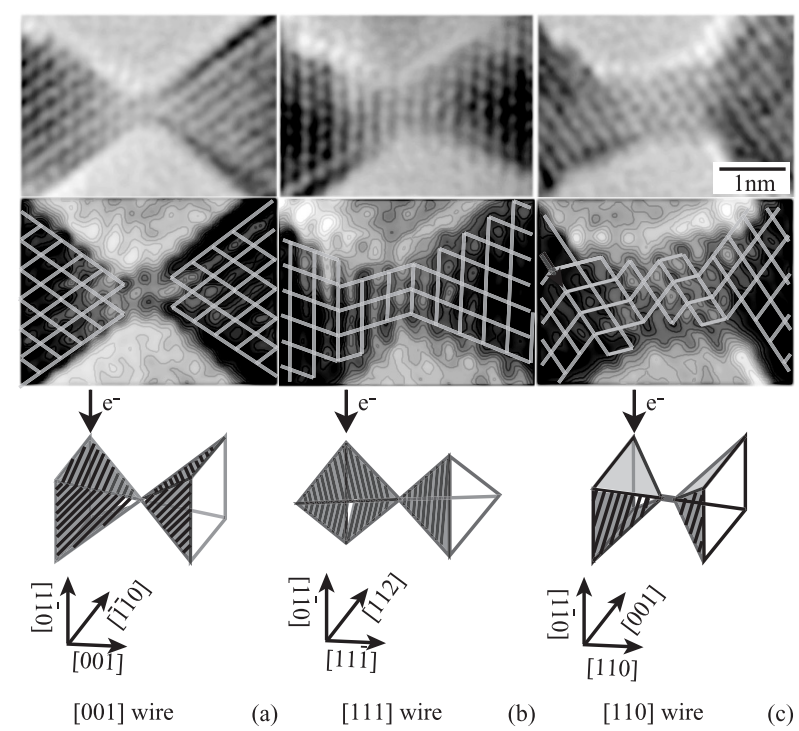

Fig. 5. (a) A typical TEM image of gold contact, which is parallel to the [001] direction of the electrodes. A narrow neck is formed in the contact. The nets represent the position of the dark dots (gold atomic column) in the gold electrodes and contact. (b) Gold contact parallel to the [111] direction of the electrodes. (c) Gold contact parallel to the [110] direction of the electrodes. A long nanowire is formed in the contact.

結晶方位 [111］に平行な軸をもつ接点であり，[001］ の場合と同様に短いナノワイヤである。電極の側面は, 3 つの $\{111\}$ 面からなっている。[111] 軸が 3 回対称 性をもつことから，この電極は，（111）層が積層してで きた正四面体形状であり, 接点は，2つの正四面体の頂 点が接するところである。TEM 像において電極側面が （001）面として見えるのは，正四面体の側面ではなく， 正四面体の稜を見ているためである（Fig. 5（b）下図参 照)。Fig. 5 (c) は, 電極の結晶方位 [110］に平行な軸 をもつ接点であり, 長いナノワイヤになる。電極の側面 は, 2 つの $\{111\}$ 面と $2 つ の ~\{001\}$ 面からなっている。 2 つの電極の接点間に長いナノワイヤができるのは, こ のワイヤが主に4つの $\{111\}$ 面で囲まれており, 安定 化していることを裏付けている。

すなわち，金接点は，最安定表面である（111）面が 優先的に現れる形状をとろうとしていることが特徵であ り，ワイヤ軸に対し平行な（111）面がない場合は，短 いナノワイヤになると解釈できる。

\section{5. 金ナノ接点構造とコンダクタンスとの関係}

Fig. 6 (a)〜 (c) は, ナノワイヤ近傍の原子が拡散に よって電極側へ移動することによって, [001］ナノワイ ヤがさらに細くなる過程を捉えた典型的な TEM 像であ 

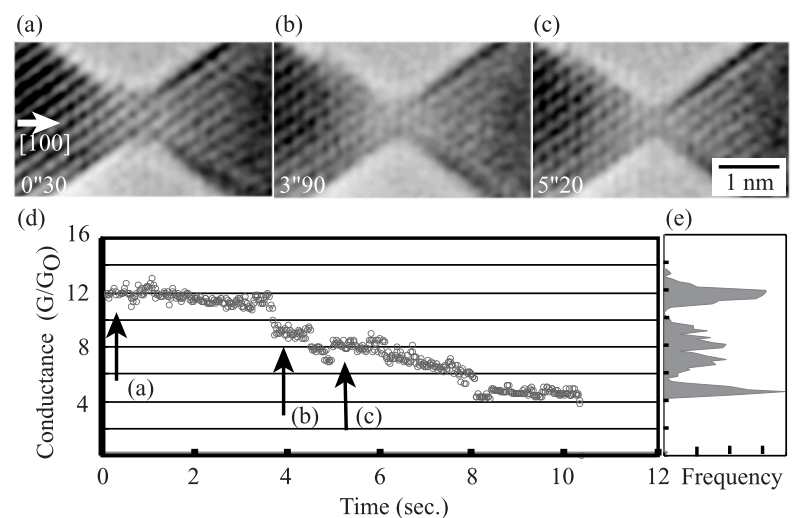

Fig. 6. Time dependent structural change in a [001] nanowire. (a), (b) and (c) are TEM images, and (d) is the conductance curve and (e) its histogram. Each TEM image is taken at the time, which is shown at the lower left-side and indicated by a corresponding arrow in (d). The width of the nanowire in (a), (b) and (c) are $1.00,0.86$, and $0.72 \mathrm{~nm}$, respectively.

り，接点におけるナノワイヤの幅が細くなる様子がわか る。Fig. 6 (d) に示すように, これらの像は, 図中に示 した時間で撮影し，また同時にコンダクタンス変化の測 定をプロットした。Fig. 6（a)，（b)，（c）と接点の幅は 小さくなっており, 断面積が減少していることがわかる。 Fig. 6 (a)，（b)，（c）におけるコンダクタンスは，それ ぞれ， $11.9 ， 9.2,8.1 \mathrm{G}_{0}$ であり，このような規則的な構 造をもつ場合のコンダクタンスは, 量子化単位 $\mathrm{G}_{0}$ の整 数倍に近い值をとることがわかった。このような不連続 なコンダクタンスの変化の途中では, コンダクタンスが 連続的に変化する部分も観察される (Fig. 6 (d) 参照)。 コンダクタンスが連続的に低下している様子を TEM 観 察で調べると, 接点を構成する原子が微小に変位してい たが，詳細な対応関係はわからなかった。Fig. 6 (e) の コンダクタンス・ヒストグラムでは， $12 ， 9 ， 8,7,5 \mathrm{G}_{0}$ にコンダクタンス・ピークを見ることができる。これら のコンダクタンスは, いずれも, 半值幅約 $0.4 \mathrm{G}_{0}$ をも っており，ブロードになっている。

Fig. 7 (a)〜 (c) は，典型的な [110］ワイヤが細くな る様子を示した TEM 像である。このナノワイヤは, 長 さがおよそ $1 \mathrm{~nm}$ である。ナノワイヤの幅が小さくなる につれて，コンダクタンスが階段状に変化した（Fig. 7 (d))。Fig. 7 (a)，（b)，（c）におけるコンダクタンスは, それぞれ，15.2，9.8，7.9 $\mathrm{G}_{0}$ であり，量子化単位 $\mathrm{G}_{0}$ の 整数倍に近い值をとる。コンダクタンスは，これら以外 の值をとらない。Fig. 7 (e) のコンダクタンス・ヒスト グラムでは, Fig. 7 (d) のコンダクタンス変化に見られ るプラトーに対応するシャープなコンダクタンス・ピー クを見ることができる。

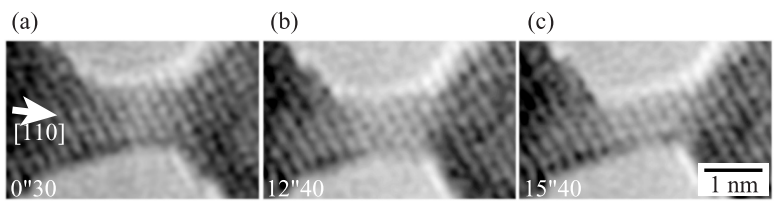

(d)

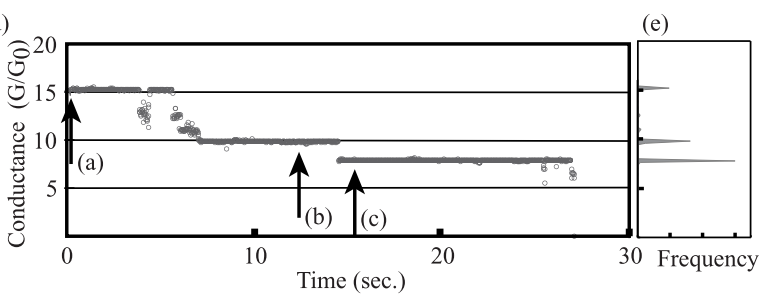

Fig. 7. Time dependent changes in a [110] gold nanowire. (a), (b) and (c) are TEM images. (d) conductance change and (e) its histogram. The width of the nanowire in (a), (b) and (c) are 1.24, 1.21, and 1.0 $\mathrm{nm}$, respectively.

電極と接点の形状を双曲線近似で表した場合，その形 状は, 最も細い部分の断面積と開き角の関数で表される。 メゾスコーピック理論によれば, 開き角が小さい場合(円 筒に近い形状)，コンダクタンスは，断面積に対し階段 状に変化するが, 開き角が大きい場合 (円錐に近い形状), コンダクタンスは, 滑らかな変化となる21)。この計算結 果は, 実験結果と定性的に一致している。Fig. 6(a), (b), (c)において，接点の幅は，それぞれ，1.0, 0.9, $0.7 \mathrm{~nm}$ であった。TEM 像からは, 3 次元的な形状を確定する ことは難しいが, 結晶の対称性やエネルギー的に安定な 構造をとることを考えれば，接点の断面は円に近いと仮 定できる。この仮定のもとでは，それぞれのコンダクタ ンスは，6，5，3 $\mathrm{G}_{0}$ （実験值，12，9，8 G0）となった。 同様に，Fig. 7 (a)，（b)，（c）において，計算より求ま るコンダクタンスは，ぞれぞれ，10，10，6 G （実験值, $15 ， 10 ， 8 \mathrm{G}_{0}$ ）となった。これらの計算結果は，実験結 果を定量的に説明することはできない。この原因として, 接点における静電ポテンシャルの幅と TEM 像から求め たナノワイヤの幅に違いがあることがあげられる。特に, 接点が短いナノワイヤの場合, 電極の静電ポテンシャル の影響もあるため, 両者の差が大きくなる可能性が高い。 さらに，メゾスコーピック理論では，電子状態の縮退に よって，9 $\mathrm{G}_{0}$ など取ることができない值がある。しか し，実験では，9 $\mathrm{G}_{0}$ などの值が観測されている。した がって，実験結果を説明するには，メゾスコーピック理 論よりさらにナノ物性に適した理論が必要と思われ $ろ^{22 \sim 24)}$ 。

これまでに，STM 法や MCBJ 法により金接点や金ナ ノワイヤのコンダクタンスが多数測定されてきた1 4)。 測定ごとにコンダクタンス変化が異なる理由は，ここで 示したように，接点の結晶方位に依存した形状の違いに 
よるものと考えられる。[001］ワイヤや [111］ワイヤ の場合, 接点は, 短いナノワイヤとなり, そのコンダク タンスは, 階段状の変化に加え, 連続的にも変化した。 つまり, ヒストグラムには, ブロードなコンダクタンス・ ピークが現れる。一方, [110] ワイヤの場合, 接点は, 長いナノワイヤとなり, そのコンダクタンスが, 階段状 に変化した。つまり，ヒストグラムには，シャープなコ ンダクタンス・ピークが現れる。STM 法や MCBJ 法で は, この両方が混在しているため, 測定ごとに異なるコ ンダクタンス変化が観察されたと推測できる。

\section{6. 結言}

今回, 透過型電子顕微鏡と走査型トンネル顕微鏡 (Scanning Tunneling Microscope: STM）を組み合わせた 手法（TEM-STM 法）を開発し, 金接点の構造とコンダ クタンスの同時測定を行った。その結果, 金接点の構造 変化に伴うコンダクタンス変化を捉えることができた。 金接点の構造は, 電極の結晶方位に依存していた。電極 [001］および [111］方位に平行な軸をもつ金接点は, 短いナノワイヤとなる。この場合, 接点が細くなる過程 で, いくつかの規則的な構造をとり, コンダクタンスは, 不連続に変化し, 量子化コンダクタンスを示すとともに, その量子化コンダクタンスの值からずれた值もとること が観察された。一方, 電極 [110］方位に平行な軸をも つ金接点は, 長いナノワイヤとなる。この場合, ナノワ イヤの幅が細くなる変化に対し, コンダクタンスは, 階 段状に変化し，量子化コンダクタンスを示した。この場 合, コンダクタンス值がある量子化コンダクタンスから ずれることは観察されなかった。このような金接点の形 状によるコンダクタンスの異なる振る舞いは, メゾスコ ーピック理論と定性的に一致している。STM 法や MCBJ 法によって得られたコンダクタンス変化が測定ごとに異 なるのは, 測定ごとに金接点の形状が異なるためと推測 される。

本研究は, 高柳邦夫教授, 平山博之助教授, 大学院生 毛利啓之助氏との共同研究によるものであり，ここに感 謝の意を表す。また, 本研究は, 文部科学省の科学研究 助成費, 特別推進研究「量子コンタクト」の助成を受け て実施された。

\section{文献}

1) N. Agraït, J.G. Rodrigo and S. Vieira: Phys. Rev. B 47,
12345 (1993).

2) J.I. Pascual, J. Méndez, J. Gómez-Herrero, A.M. Baró and N. García: Phys. Rev. Lett. 71, 1852 (1993).

3) L. Olesen, E. Laegsgaard, I. Tensgaard and F. Besenbacher: Phys. Rev. Lett. 72, 2251 (1994).

4) J.M. Krans, C.J. Muller, I.K. Yanson, Th. C.M. Govaert, R. Hesper and J.M. van Ruitenbeek: Phys. Rev. B 48, 14721 (1993).

5) D. Sánchez-Portal, C. Untiedt, J.M. Soler, J.J. Sáenz and N. Agraït: Phys. Rev. Lett. 79, 4198 (1997).

6) J.C. Cuevas, A.L. Yeyati, A. Martín-Rodero, G.R. Bollinger, C. Untiedt and N. Agrait: Phys. Rev. Lett. 81, 2990 (1998).

7) N. Kobayashi, M. Brandbyge and M. Tsukada: Phys. Rev. B 62, 8430 (2000).

8) S.K. Nielsen, M. Brandbyge, K. Hansen, K. Stokbro, J. M. van Ruitenbeek and F. Besenbacher: Phys. Rev. Lett. 89, 066804 (2002).

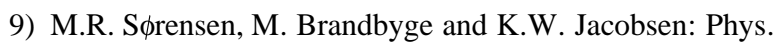
Rev. B 57, 3283 (1998).

10) A. Hasmy, E. Medina and P.A. Serena: Phys. Rev. Lett. 86, 5574 (2001).

11) M. Kuwabara, W. Lo and J.H.C. Spence: J. Vac. Sci. Technol. A 7, 2745 (1989).

12) M. Iwatsuki, K. Murooka, S. Kitamura, K. Takayanagi and Y. Harada: J. Electron. Microsc. 40, 48 (1991).

13) Y. Naitoh, K. Takayanagi, H. Hirayama and Y. Oshima: Surf. Sci. 433-435, 627 (1999).

14) H. Ohnishi, Y. Kondo and K. Takayanagi: Nature 395, 780 (1998).

15) T. Kizuka, K. Yamada, S. Deguchi, M. Naruse and N. Tanaka: Phys. Rev. B 55, R 7398 (1997).

16) D. Erts, H. Olin, L. Ryen, E. Olsson and A. Thölén: Phys. Rev. B 61, 12725 (2000).

17) Y. Oshima, K. Mouri, H. Hirayama and K. Takayanagi: Surf. Sci. 531, 209 (2003).

18) K. Takayanagi, Y. Kondo and H. Ohnishi: Proc. of Electron Microscopy and Microanalysis (1998) p. 701.

19) K. Hansen, S.K. Nielsen, M. Brandbyge, E. Lægsgaard, I. Stensgaard and F. Besenbacher: Appl. Phys. Lett. 77, 708 (2000)

20) D.J. Bakker, Y. Noat, A.I. Yanson and J.M. van Ruitenbeek: Phys. Rev. B 65, 235416 (2002).

21) J.A. Torres, J.I. Pascual and J.J. Sáenz: Phys. Rev. B 49, 16581 (1994).

22) M. Okamoto and K. Takayanagi: Phys. Rev. B 60, 7808 (1999).

23) N.D. Lang and Ph. Avoris: Phys. Rev. B 62, 7325 (2000).

24) N. Kobayashi, M. Brandbyge and M. Tsukada: Phys. Rev. B 62, 8430 (2000). 